Article

\title{
Effects of cultural capital on children's educational success: An empirical study of Vietnam under the shadow of Bourdieu's cultural reproduction theory.
}

\author{
Truong Thi Hong Thuy \\ School of Education Science, Minan Normal University, Zhangzhou, P.R. China; truongthihongthuy23@gmail.com \\ Corresponding: Truong Thi Hong Thuy truongthihongthuy23@gmail.com, Tel: +86-18652831373
}

\begin{abstract}
One of the robust explanation related to sociological educational inequality is Bourdieu's cultural reproduction theory. Admittedly, prior work investigated that children's cultural capital (CC) have significant effects on educational success. Although, it remain unclear in the context of developing countries specifically Vietnam. Also, how children's conversion mechanism of CC works and drive educational success. Meanwhile, Bourdieu theory argue that CC effects educations outcomes largely via teachers biasness by using support of school grades, in contrast some of the scholars argue that absorption of children's CC may directly transmit into educational abilities and skill development. This study employed partial least square structural equation modelling to analyze $5^{\text {th }}$ grades students' data collected from educational policy and data center. This study argue that conversion mechanism grounded on CC dimensions. This study provide implications for the policy makers and future researchers.
\end{abstract}

Keywords: Children beaux-arts consumption; parents' education; cultural capital theory; children educational performance; children reading behavior.

\section{Introduction}

Bourdieu's cultural reproduction theory (BCRT) is considered one of the dominant explanation of social inequality in education [1,2]. BCRT stated that social class deviations in educational results arise due to paternal/maternal unequal possession of cultural capital (CC). Middle class families, who are estimated to be more accustomed with the legitimate culture, transmit their $\mathrm{CC}$ to their kids through active socialization such as taking kid to the museum and passive role modeling reading newspapers and books. In return child convert their CC into educational results in the school settings. More profoundly, Bourdieu schools are middle class institution which presume and rewards CC and acquaintance with the legitimate culture of prominent class [3].

BCRT inspired a great amount of studies, which mainly support his argument [4,5]. Although, many scholars have identified a link between CC (i.e. beaux-arts consumption, reading habits, visiting museum) and educational consequences, it endured under disagreement how child convert their CC into educational success [6-8].

Bourdieu played significant impacts on symbolic value of CC: CC has significant effects on academic results as it embodies higher social class association and leads instructor/teacher to misconceive children's CC as educational intelligence $[9,10]$. Henceforth, CC is arbitrary in the perspective that it gains its importance from its appreciation by the dominant class. CC has application in the context of school, as generally schools are not socially neutral institutions albeit reveals an experience of prominent class [11, 12]. In particular, students who are not socialized into the attitude, preference, and behavior of middle class, therefore will fight to confirm towards the expectancy of the educational system. Hence, schools 
according to $[13,14]$, appear to be meritocratic bodies, though they discriminate against conserve inequalities and working class children. A plethora of empirical and theoretical work is grounded on such considerations, and in particular not all stick with concept of CC. However, some scholars, for instance assume that CC has intrinsic value and improve educational outcomes via directly subsidizing to children's skill development $[15,16]$. This viewpoint inherently ague that skills for example mathematic and linguistic competences, are non-arbitrary, generally accessible and therefore develop the meritocratic legitimation of social selection. However, the debate is continuing around the question whether symbolic and real CC can be differentiated $[17,18]$. The contribution of this study make these distinction, and also acknowledge that present study approach differentiate from the more orthodox reading of CC theory.

Prior studies, proposed that both mechanism are at work. Research that reflects a positive link between CC and objective ability measure sustenance the idea of skill generating function of CC [19, 20]. In contrast, studies that reveals a positive relationship between CC and subjective performance measure for instance teacher grades, controlling for objective ability measures, backing the indication of symbolic function of CC $[5,21]$.

Henceforward, to investigate under which conditions CC has a skill generating or symbolic function, it is critical to focus on dimensions of CC. Scholars have argued that the conversion mechanism of CC grounded on the type of CC $[22,23]$. Most importantly, CC which consists the consumption of culture (such as museum or classical concert and visiting theatre) have less contribution to children's skill development comparative to productive cultural activities (for instance, performing arts, reading books and attending visual classes). Thus, this study aim to answer following questions

1. Do distinct dimensions of CC deviate in the degree to which they produce skills?

2. Does the emblematic value of distinct dimension of CC continue once objective measures of educational skills taken into account?

To response above questions, this study employ test to which extent the two CC dimensions are pertinent to two types of academic outcomes that vary in their subjectivity standardized ability test (objective measure) score and grades (subjective measure). This study propose that consumption dimension is not or only poorly linked with test scores, albeit works through its symbolic value and is thus linked with teacher assessments. In particular, the productive dimension is probably to be highly linked to test score due to fact that it directly decode into the skills that are needed and rewarded in schools. Furthermore, this work tested in Vietnam, as [24], proposed that educational work in Vietnam deprived of lack of collaboration, technical knowledge, and qualified teachers are critical issues and challenges.

This paper continues with literature review containing theoretical support and hypotheses development. It then details the methodology and result analysis. This article end with summary and conclusion.

\section{Literature review}

\subsection{Theoretical support}

Cultural capital theory refers to the significance of socialization into highbrow activities, such as interest in classical music and arts, museum and theatre visit, and reading books [25]. This theory argue that children's who are not familiar with such types of socialization will experience school as a hostile environment. More profoundly, they lack habits, styles, and skills that are rewarded in educational settings. The resultant of it includes that they will refrain from higher education, and if they involve in education they will not get expected outcomes or may not be appreciated by teachers [22].

[21], initially conducted research on the impacts of CC on educational achievement/success. The researcher found that cultural possessions improve academic outcomes (grades) even when the effects of prior ability and parents education is taken into account. While BCRT holds that parents CC is more favorable for children's from high social backgrounds. Furthermore, those who don't have suitable socialization, due to their inferior social backgrounds will not gains as much from their parents CC 
comparative to children's who have appropriate socialization. Still the debate is continuing about the concept and measurement of CC. [22], defined CC as "institutionalized, i.e. widely shared, high status cultural signals (attitudes, preferences, formal knowledge, behaviors, goods and credentials) used for social and cultural exclusion." (p. 156). Bourdieu's work carries the multi-dimensional and more complex nature of the term CC and its contents, quantitative investigation mainly lapses to simplify the CC and usually emphasis on cultural activities (e.g. reading, possession of artwork, books, musical instruments, active and passive involvement in attaining visuals and performing arts) [26]. [17], suggested that mainly quantitative methods vary from inherent concept of CC in a stagnant Bourdieusian viewpoint. Authors, proposed that $\mathrm{CC}$ is not a separated property of individuals albeit rather gains its value via individuals action and interaction in particular situation. Moreover, conventional survey based assessments however are unable to fully translate the orthodox interpretation of CC. Therefore, notwithstanding the challenging task of a accomplishing operationalization and assessment, this study will emphasis on quantitative methods and continue the existing literature.

Early researchers $[27,21]$, for instance use reading frequency or involvement/participation in high arts (for example visiting opera, theatre, and museum) and number of books at home. [28], extends this context and climax the distinct among taking cultural classes and consuming high arts. In distinction to cultural consumption they relate taking classes as a highly conscious investment in forming culture. However, most of scholars refer to this deviation, the outcome of which such studies remained indecisive. This possibly is given the fact the cultural participation is operationalized in several ways, and as scholars employed many distinct results measures. For instance some employed educational attainment (i.e. achieving a high school, or entering college or college degree as dependent variable). While other employed grades or test scores. The difference among active and passive cultural participation also covered in distinct ways: some scholars referred to cultural trips and classes [29, 30] or discuss about the culture from family viewpoint [31, 32].

Notwithstanding, distinct operationalization's, the majority of research found a positive relationship between CC and several educational outcomes measure [33]. An exception symbolizes the investigation that measured the CC as a two sided dimensional variable reading behavior and beaux-arts consumption. Prior work applying this difference found that reading behavior was dominant forecaster of high educational results than beaux-arts consumption [34]. Similarly, work differentiate the active cultural participation and cultural consumption reflects that active cultural participation becomes a dominant forecaster of educational outcome [35].

Such findings raised the doubt about the mere symbolic value of CC. [36, 37], criticized BCRT idea that CC is always in a significant sense arbitrary. Author argued that it's not mandatory that all form of CC are arbitrary; some forms of CC may have intrinsic value. For example, reading act is considered a form of CC, and is at the same time of intrinsic value as it leads to children's language skills and reading [38].

Some of the scholars yet draw on the BCRT idea of symbolic function of CC in the classroom; reflecting $\mathrm{CC}$ in the school setting may be employed as a signal of high school status to teachers, who compensate students for revealing their knowledge of the legitimate culture [5]. Hence, from this viewpoint, CC is completely arbitrary and has intrinsic value given its appreciation and legitimization through prominent groups [39]. For example, parents and their children's shows their CC when interacting with teachers in school, and such behavior may affect the assessment of a child and teachers impression. This mechanism however argue that teachers are biased towards students who adopt and shows middle class behavior.

A particular strategy to test the symbolic function of CC is to regress educational attainment or children's grades on their CC, controlling for the competence test scores. In fact, prior work have reflected that children's CC is significantly link with educational performance on average, net of objective ability assessment [40]. Scholarships investigating the skill producing function of CC regress standardized ability test scores on children's CC. They have been able to reflect that CC also is pertinent to higher educational skills [41, 42]. Nevertheless, these scholarships demonstrate that both conversion mechanism are at work. Meanwhile, to the best of our knowledge, there is no any scholarship which investigate the link between distinct dimension of CC and distinct conversion mechanism simultaneously. 
To test association between CC dimension and their conversion mechanism, it is mandatory to investigate how two CC dimensions are link with educational performance measure of distinct degrees of subjectivity. Moreover, testing the symbolic function of CC necessitate a subjective academic performance measures that can detention teachers biases (grades); testing skill producing function necessitate an objective ability measures (anonymous and standardized test). Thus to investigate the argument that two CC dimensions regards to educational success through two distinct channels.

\subsection{Hypotheses development}

To test the association among CC dimension and their conversion mechanism, we test following: If CC takes place through its symbolic function, beaux-arts consumption will be related with greater teacher performance ratings. In comparative, if reading behavior straight forwardly arouse children's competence development, reading act will be linked with greater competence test scores of children educational ability (CEA) which is irrespective of teachers biased perception [43]. Henceforth, following hypotheses will be tested

H1a: Children's reading behavior is significantly linked with competence test scores.

Moreover, this study predict that beaux-art consumption includes less active learning, cultural practice, and cognitive activation, and thus contribute only little to student's skill development. Therefore we proposed that.

H1b: Student's beaux-arts consumption is linked with children's competence test scores.

The grades represents the subjective measures of educational performance than ability tests. Therefore, grades may be impacted by teachers' biased perception. Indeed, the grades in distinct subjects possible deviate in the extent to which they demonstrate subjective bias [44], for instance suggested that math grades are less vulnerable to subjective evaluation than grades in English. However, Vietnam grades are particularly well suited to investigate the symbolic function of students' cultural consumption.

Though, this study predict that reading behavior is skill producing, this doesn't exclude that familiarity with existing scholarship signals CC in context of classroom. Children's who read not only be benefited in form of ability albeit may also be more confident and eloquent in classroom. Thus, this study proposed that;

H2a: children's reading act is significantly link with their grades, despite of controlling for competence test scores.

Present scholarship argued that beaux-arts consumption is not skill producing, while familiarity with legitimate culture may not be profitable in class. BCRT theory proposed that such type of CC signals middle class association and produce a significant bias in teachers, which will be demonstrated in grades, whereas not in actual skills. Hence, study proposed that

H2b: Students' beaux-art consumption is significantly linked with schools grades despite of controlling competence test scores.

H3a: Parents' reading behavior mediate between the parents' education and children's reading behavior.

H3b: Parents' beaux-arts CC mediate between the parents' education and children's beaux-arts CC. 


\subsection{Conceptual framework}

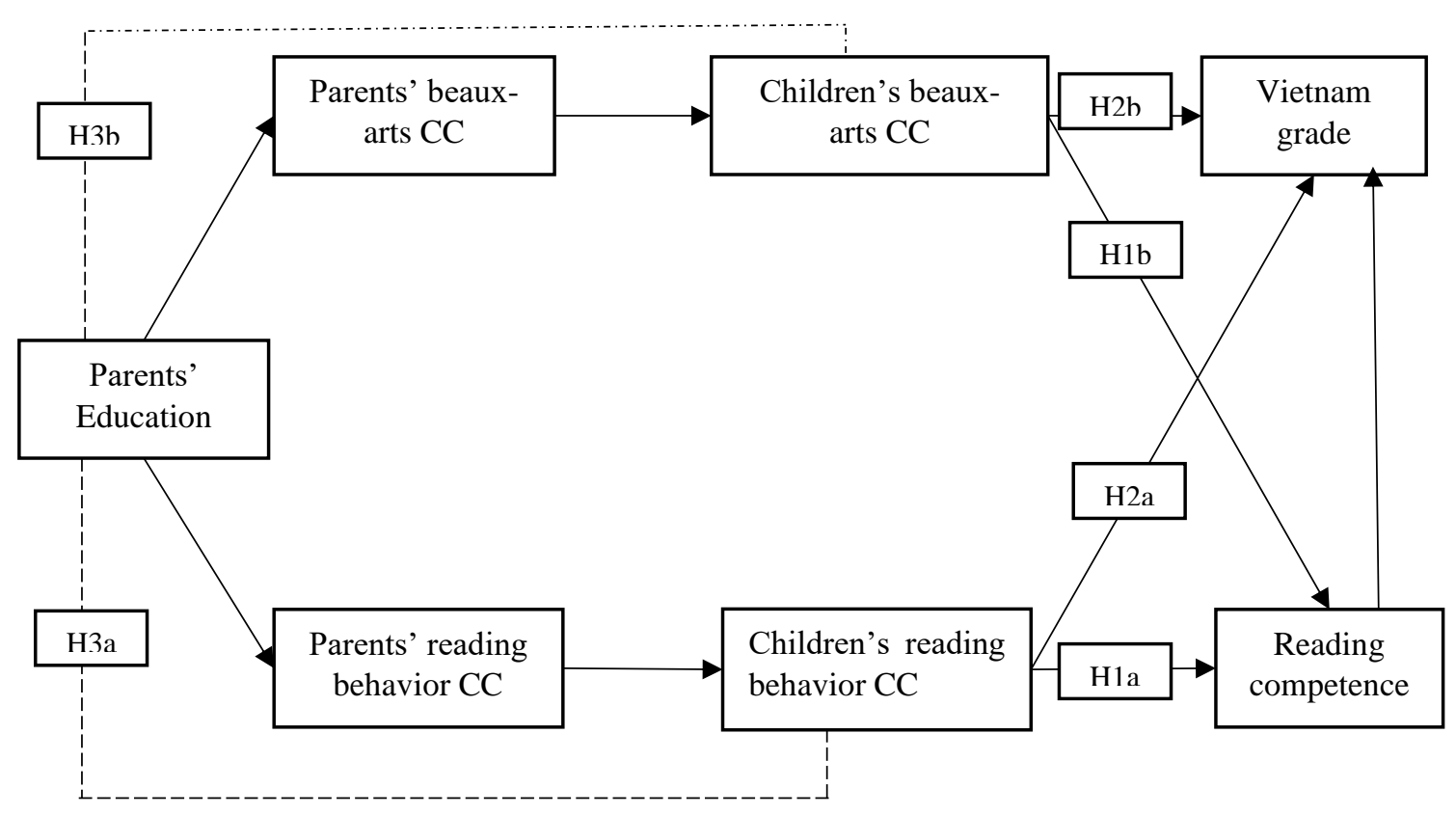

\section{Methodology}

\subsection{Data collection}

Education policy and data center is an online platform/web-portal which provides valid information related to educational policies and schooling system [45]. Also [46] provides related information more particularly on the educational process, competencies, and family environment of children's/students' enrolled/started $5^{\text {th }}$ grades in 2020 in Vietnam. Indeed, data set involve a sample of $5^{\text {th }}$ grades in all educational tracks of school system in Vietnam. The measurements consisted standardized competence test for reading, math, and cognitive abilities and open-ended questionnaire directed to children, their teachers, caretakers, and principals. A stratified random sampling approach employed in two stages; in the $1^{\text {st }}$ stage schools were randomly selected via employing probability proportional to size sampling, and in $2^{\text {nd }}$ stage, two classrooms were selected in each school [47]. Furthermore, this study used the interview data from caretaker and the specific child from wave 1,3, and 4. Moreover, keeping in view item rotation wave 2 did not contains key measure. In the first round 3,859 school children and their parents called for an interview. All were shuffled in 438 classes and 229 schools. Due to using proposed filters sample size decreased to 2,418 children's and their parents in wave 4 . This study conducted extra analysis employing full information maximum possibility to test for bias as item and wave non-response. The outcome did not fluctuate qualitatively and are further explained in sensitivity analysis given below.

\subsection{Measures of the study}

Children's educational performance (CEP) was evaluated with grades in Vietnam. In Vietnam, grads are not grounded on standardized measurements and hence, are likely to demonstrate children's characteristics afar from educational ability [48, 49]. Aforementioned, we selected grades as outcome assessor as these are specifically related to detention teacher subjectivity. The collected data includes Vietnam grade information stated by children and their parents. To ensure time series slit among present study dependent and independent constructs, this study employed grades at the end of $7^{\text {th }}$ grades, assessed in wave 4 ( $8^{\text {th }}$ grade). Both, parents' and children's stated on grades are inclined to assessment error, because of social desirability and memory effects. Hence, we employed children's and their parents' 
response to build a latent construct for Vietnam educational performance. For clear enlightens and interpretation of outcomes we convert grades so that higher scores infer greater performance. Scale includes 5 range, where $1=$ very good, and $5=$ poor.

Children's educational ability was measured with weighted probability assumption [50] of test scores in reading delivered by educational policy and data center in wave 3 ( $7^{\text {th }}$ grades). Comparatively to schools grades suggested by teachers, such test were intended by educational policy and data, thus it exhibits a more objective assessor of actual abilities. The test included comprised of thirty three items distinct in task type and test type. Indeed, technical reports reveals the detailed narration related to reading test scores [51].

Children's beaux-arts consumption ( $\mathrm{CBC}$ ) was assessed with students' response to 3 items on visiting/attending ( $1=$ museum, $2=$ theatre, and $3=$ classical concerts opera/other performance). This scale rated on 5 point where $1=$ never and $5=$ greater than 5 times in a year.

Children's reading behavior (CRB) was evaluated via two items. These items includes information about the time students' spent reading outside the school. The items measured by 5 point scale where 1 $=$ not at all and $5=$ greater than 2 hours.

\subsection{Other constructs}

This study used additional variables to analysis to decrease bias of mislaid constructs, and to enlighten cultural reproduction mechanism. Moreover, study contains parental CC as mediator among parents' academic and children's CC. parental beaux-arts consumption assessed by 3 items where 1 =museum, 2 $=$ theatre, and $3=$ classical concert/other performance). The 5 point scale used to assess the items. The scale rated as $1=$ never and $5=$ greater than 5 times in a year.

And the reading behavior of parents measured by 2 items. These items includes information about the time durations parents' spent reading books. The items measured by 5 point scale where $1=$ not at all and 5 =greater than 2 hours. Additionally, parents' education assessed by number of years of academics in the family $[52,53]$.

\subsection{Analyzing tools}

This study employed partial least square structural equation modelling (PLS-SEM). This tool is widely accepted and employed in recent studies [54], and in several disciplines [55-57]. Moreover, structural equation modelling enables researchers to simultaneously predict how parsimonious dimensions of children's CC related to Vietnam grades, reading test sores, and unravel direct as well as indirect paths.

This study used two steps analysis. Initially, study evaluate the suitability of hypothesized model 4 variables by using confirmatory factor analysis (CFA). Then, study employed complete SEM with direct pathways from CRB to reading scores-H1a, and direct link from CBC to Vietnam grades-H2b. study also included direct path from reading behavior to Vietnam grades-H2a, and beaux-arts consumption to reading scores- $\mathrm{H} 2 \mathrm{~b}$.

\section{Results analysis}

For results analysis we have employed partial least square structural equation modelling (PLS-SEM). Several tests conducted related to reliability, validity, and path coefficients. Also to ensure the data free from multicollinearity and other data related bias were measured [58]. The analysis section utilized a twoway approach to assess the results. Assessment of measurement model and (2) Structural model, [58].

\subsection{An assessment of the Measurement Model}

As per [59] suggestions in order to measure the model of study scholars are required to assess the "individual item reliability, content validity, convergent validity, and discriminant validity". 


\subsubsection{Individual item reliability}

According to [60], the value of Cronbach's Alpha (CA) should be greater than 0.7. The values of CA retained between 0.85 and 0.94 . Therefore, it is concluded that the study adequately meets the standard of reliability of the measures.

\subsubsection{Internal consistency reliability}

[61] proposed that the value of composite reliability (CR) should be equivalent to or exceeds 0.7. Table 1 exhibited the CR of the constructs, retained between 0.89 and 0.95 , proposing the adequate reliability of the measures.

\subsubsection{Convergent validity}

According to [62], rule of thumb the value of AVE, should be equivalent to 0.5 or above. The value of AVE of the study, retained between 0.62 and 0.86 henceforth; it is concluded that this work qualify the satisfactory level of convergent validity.

Table 1. Measurement Model.

\begin{tabular}{lccc}
\hline Observed and latent constructs & CA & CR & AVE \\
\hline Children's beaux-arts CC & 0.94 & 0.95 & 0.74 \\
\hline Parents' beaux-arts CC & 0.89 & 0.93 & 0.82 \\
\hline Parents' education & 0.93 & 0.95 & 0.71 \\
\hline Parents' reading behavior CC & 0.9 & 0.93 & 0.77 \\
\hline Children's reading behavior CC & 0.92 & 0.95 & 0.86 \\
\hline Reading test score & 0.87 & 0.92 & 0.79 \\
\hline Vietnam grade & 0.85 & 0.89 & 0.62 \\
\hline
\end{tabular}

\subsubsection{Discriminant validity}

Two methods were used to evaluate the "discriminant validity" of the variables. 1) It was ensured that the cross-loadings of indicators should be higher than any other opposing constructs. According to the [62]criterion, the square root of AVE for each construct should exceed the inter-correlations of the construct with other model constructs". Therefore, as shown in Table 2 . It could be concluded that all the constructs employed in the work have adequate level of discriminant validity.

Table 2. Latent variable correlation and square root of AVE.

\begin{tabular}{lrrrrrrr}
\hline Observed and latent constructs & $\mathbf{1}$ & $\mathbf{2}$ & $\mathbf{3}$ & $\mathbf{4}$ & $\mathbf{5}$ & $\mathbf{6}$ & $\mathbf{7}$ \\
\hline Children's beaux-arts CC & 0.86 & & & & & & \\
\hline Parents' beaux-arts CC & 0.71 & 0.9 & & & & & \\
\hline Parents' education & 0.45 & 0.46 & 0.85 & & & & \\
\hline Parents' reading behavior CC & 0.29 & 0.25 & 0.56 & 0.88 & & & \\
\hline Children's reading behavior CC & 0.65 & 0.72 & 0.5 & 0.28 & 0.93 & & \\
\hline Reading test score & 0.75 & 0.74 & 0.46 & 0.29 & 0.64 & 0.89 & \\
\hline Vietnam grade & 0.65 & 0.6 & 0.39 & 0.28 & 0.58 & 0.62 & 0.79 \\
\hline
\end{tabular}




\subsection{An assessment of the Structural Model}

This article utilized PLS bootstrapping with 1000 bootstraps and 423 cases with the motive to analyze the hypothesized model and its significance [59]. Figure 1 demonstrate the comprehensive illustration of assessments of the structural model alongside with statistics related to moderation trust and charge/price.

\subsubsection{Collinearity issue of structural model}

To ensure the multicollinearity issue, editors and scholars requires HTMT (Heterotrait-Monotrait) ratio, [63] proposed that it value of the constructs should not exceed 0.9. Table 3 showed that the maximum value of a construct found 0.85 , henceforth this study is free from multicollinearity issue.

Table 3. Heterotrait-Monotrait Ratio.

\begin{tabular}{lrrrrrrr}
\hline Observed and latent constructs & $\mathbf{1}$ & $\mathbf{2}$ & $\mathbf{3}$ & $\mathbf{4}$ & $\mathbf{5}$ & $\mathbf{6}$ & $\mathbf{7}$ \\
\hline Children's beaux-arts CC & & & & & & & \\
\hline Parents' beaux-arts CC & 0.78 & & & & & \\
\hline Parents' education & 0.48 & 0.5 & & & & & \\
\hline Parents' reading behavior CC & 0.32 & 0.27 & 0.6 & & & \\
\hline Children's reading behavior CC & 0.69 & 0.79 & 0.54 & 0.3 & & \\
\hline Reading test score & 0.83 & 0.85 & 0.51 & 0.32 & 0.72 & \\
\hline Vietnam grade & 0.72 & 0.69 & 0.43 & 0.33 & 0.66 & 0.73 \\
\hline
\end{tabular}

\subsubsection{Coefficient of determination, Inner VIF, f2, and model fit}

To evaluate the variance of the constructs, PLS-SEM suggest evaluating the R2 coefficient, which also called the coefficient of determination [64]. According to [65], the value of R2 0.60, 0.33 and 0.19 respectively set as rule of thumb and these values described as substantial, moderate and weak. [58] proposed that the $\mathrm{R} 2$ coefficient is subject to the situation where a specific study is conducted. However, as per [66], recommendation R2 coefficients of 0.10 is also acceptable. Meanwhile, as reflected in Table 4 the present study $\mathrm{R} 2$ retained between 0.08 and 0.61 . The value of 0.61 indicates that $61.0 \%$ variation in reading test scores occurred due to educational performance, PRB CC, CRB CC, and CBC.

\subsubsection{The Effect Sizes (f2)}

In order to examine the R2 values of all endogenous constructs, the change in the R2 value when a specified exogenous construct is omitted from the model can be used to evaluate whether the omitted construct has a substantive impact on the endogenous constructs. This measure is mostly preferred by editors and reviewers. In addition, the values of $0.02,0.15$, and 0.35 , respectively, represent small, medium, and large effects [67]. If the value of $\mathrm{f} 2$ is $<0.02$, it indicates that there is no effect. The results of the study shown in Table 4 proved that there is a large and small effects.

Table 4. Coefficient of determination.

\begin{tabular}{lcccc|c}
\hline $\begin{array}{l}\text { Observed and latent } \\
\text { constructs }\end{array}$ & $\mathbf{R}^{\mathbf{2}}$ & $\mathbf{R}^{2}$ Adjusted & $\begin{array}{c}\text { Inner } \\
\text { VIF }\end{array}$ & $\mathbf{f}^{2}$ & \multicolumn{2}{c}{$\begin{array}{c}\text { SRMR- } \\
\text { Model fit }\end{array}$} \\
\hline Children's beaux-arts CC & 0.51 & 0.51 & 1.72 & 0.50 (large) & \multirow{2}{*}{$\mathbf{0 . 0 4}$} \\
\hline Parents' beaux-arts CC & 0.21 & 0.21 & 1.72 & & \\
\cline { 1 - 4 } Parents' reading behavior CC & 0.31 & 0.31 & 1.0 & 1.04 (large) & \\
\hline
\end{tabular}




\begin{tabular}{|c|c|c|c|c|}
\hline $\begin{array}{l}\text { Children's reading behavior } \\
\text { CC }\end{array}$ & 0.08 & 0.08 & 1.0 & 0.11 (small) \\
\hline Reading test score & 0.61 & 0.61 & 2.56 & \\
\hline Vietnam grade & 0.49 & 0.48 & & \\
\hline
\end{tabular}

\subsubsection{Predictive relevance of the model}

Keeping in view the reflective nature of measures, this study employed cross-validated redundancy measure $\mathrm{Q}^{2}$, for evaluating the model as per suggestions of [68]. It is an indicator of the model's out-ofsample predictive power or predictive relevance given by $[69,70] \mathrm{Q}^{2}$ value. In the structural equation model, $\mathrm{Q}^{2}$ values larger than zero for a specific reflective endogenous latent variable indicate the path model's predictive relevance for a particular dependent construct. Moreover, As a relative measure of predictive relevance, $q 2$ values of $0.02,0.15$, and 0.35 , respectively, indicate that an exogenous construct has a small, medium, or considerable predictive relevance for a specific endogenous construct. Hence, as reflected in Table 5 the results of the study shows that model has medium predictive relevance.

Table 5. The Predictive Relevance (Q2) Effect Sizes.

\begin{tabular}{lccc}
\hline Observed and latent constructs & SSO & SSE & $\mathbf{Q}^{\mathbf{2}}$ (=1-SSE/SSO) \\
\hline Children's beaux-arts CC & $2,961.00$ & $1,931.44$ & 0.35 \\
\hline Children's reading behavior CC & $1,269.00$ & $1,190.67$ & 0.06 \\
\hline Parents' education & $2,961.00$ & $2,961.00$ & \\
\hline Parents' beaux-arts CC & $1,269.00$ & $1,064.40$ & 0.16 \\
\hline Parents' reading behavior CC & $1,692.00$ & $1,315.39$ & 0.22 \\
\hline Reading test score & $1,269.00$ & 692.75 & 0.45 \\
\hline Vietnam grade & $2,115.00$ & $1,515.86$ & 0.28 \\
\hline
\end{tabular}

Table 6. Path coefficients and hypotheses testing.

\begin{tabular}{|c|c|c|c|c|c|c|c|}
\hline Hypotheses & Relationship & Beta & Mean & SD & t-value & $\begin{array}{c}\mathrm{p}- \\
\text { value }\end{array}$ & Decision \\
\hline \multicolumn{8}{|l|}{ Direct Effect } \\
\hline $\mathrm{H} 1 \mathrm{a}$ & $\begin{array}{l}\text { Children's reading behavior CC } \\
->\text { Reading test score }\end{array}$ & 0.152 & 0.15 & 0.04 & 6.12 & $0.011^{*}$ & Supported \\
\hline $\mathrm{H} 1 \mathrm{~b}$ & $\begin{array}{l}\text { Children's beaux-arts CC -> } \\
\text { Reading test score }\end{array}$ & 0.192 & 0.19 & 0.04 & 15.05 & $0.001^{*}$ & Supported \\
\hline $\mathrm{H} 2 \mathrm{a}$ & $\begin{array}{l}\text { Children's reading behavior CC } \\
\text {-> Vietnam grade }\end{array}$ & 0.373 & 0.37 & 0.05 & 6.2 & $0.000^{*}$ & Supported \\
\hline $\mathrm{H} 2 \mathrm{~b}$ & $\begin{array}{l}\text { Children's beaux-arts CC -> } \\
\text { Vietnam grade }\end{array}$ & 0.275 & 0.27 & 0.05 & 9.66 & $0.000^{*}$ & Supported \\
\hline \multicolumn{8}{|c|}{ Indirect / Mediating Effect } \\
\hline $\mathrm{H} 3 \mathrm{a}$ & $\begin{array}{l}\text { Parents' education -> Parents' } \\
\text { beaux-arts CC -> Children's } \\
\text { beaux-arts CC }\end{array}$ & 0.33 & 0.33 & 0.04 & 8.3 & $0.000^{*}$ & Supported \\
\hline $\mathrm{H} 3 \mathrm{~b}$ & $\begin{array}{l}\text { Parents' education -> Parents' } \\
\text { reading behavior CC -> } \\
\text { Children's reading behavior CC }\end{array}$ & 0.15 & 0.16 & 0.04 & 4.19 & $0.000^{*}$ & Supported \\
\hline
\end{tabular}




\begin{tabular}{|c|c|c|c|c|c|c|c|}
\hline \multicolumn{8}{|c|}{ Note: ${ }^{*} p<0.05$ (two-tailed test) } \\
\hline Hypotheses & Relationship & Beta & Mean & SD & t-value & $\begin{array}{c}\mathrm{p}- \\
\text { value }\end{array}$ & Decision \\
\hline \multicolumn{8}{|l|}{ Direct Effect } \\
\hline H1a & $\begin{array}{l}\text { 幼儿阅读行为的文化资本 -> 阅读 } \\
\text { 测试成绩 }\end{array}$ & 0.152 & 0.154 & 0.06 & 2.538 & $0.011^{*}$ & Supported \\
\hline $\mathrm{H} 1 \mathrm{~b}$ & $\begin{array}{l}\text { 幼儿美术文化资本 -> 阅读测试成 } \\
\text { 绩 }\end{array}$ & 0.192 & 0.193 & 0.059 & 3.234 & $0.001^{*}$ & Supported \\
\hline $\mathrm{H} 2 \mathrm{a}$ & $\begin{array}{l}\text { 幼儿阅读行为的文化资本 -> 越南 } \\
\text { 的水平 }\end{array}$ & 0.373 & 0.37 & 0.048 & 7.687 & $0.000^{*}$ & Supported \\
\hline $\mathrm{H} 2 \mathrm{~b}$ & 幼儿美术文化资本 -> 越南的水平 & 0.275 & 0.273 & 0.05 & 5.525 & $0.000^{*}$ & Supported \\
\hline \multicolumn{8}{|c|}{ Indirect / Mediating Effect } \\
\hline H3а & $\begin{array}{l}\text { 父母的教育 -> 父母艺术文化资本 } \\
\text {-> 幼儿美术文化资本 }\end{array}$ & 0.474 & 0.475 & 0.037 & 12.809 & $0.000^{*}$ & Supported \\
\hline $\mathrm{H} 3 \mathrm{~b}$ & $\begin{array}{l}\text { 父母的教育 }->\text { 父母阅读行为的文 } \\
\text { 化资本 -> 幼儿阅读行为的文化资 } \\
\text { 本 }\end{array}$ & 0.324 & 0.324 & 0.04 & 8.07 & $0.000^{*}$ & Supported \\
\hline
\end{tabular}

\subsection{The Structural Equation Model}

This study employed PLS-SEM to test a constructed model that at one side showed a significant association between parents' education and parents beaux-arts $C C(p=0.000)$; parents beaux-arts $C C$ and CBC $(p=0.000) ; C B C$ and Vietnam grades $(p=0.000)$. On other side, shows positive association between parents' education and parents' reading behavior $\mathrm{CC}(\mathrm{p}=0.000)$; parents' reading behavior $\mathrm{CC}$ and $\mathrm{CRB} C \mathrm{C}$ $(\mathrm{p}=0.000)$; $\mathrm{CRB} C \mathrm{C}$ and reading test scores $(\mathrm{p}=0.000)$; and reading test scores and Vietnam grades $(\mathrm{p}=0.000)$. 

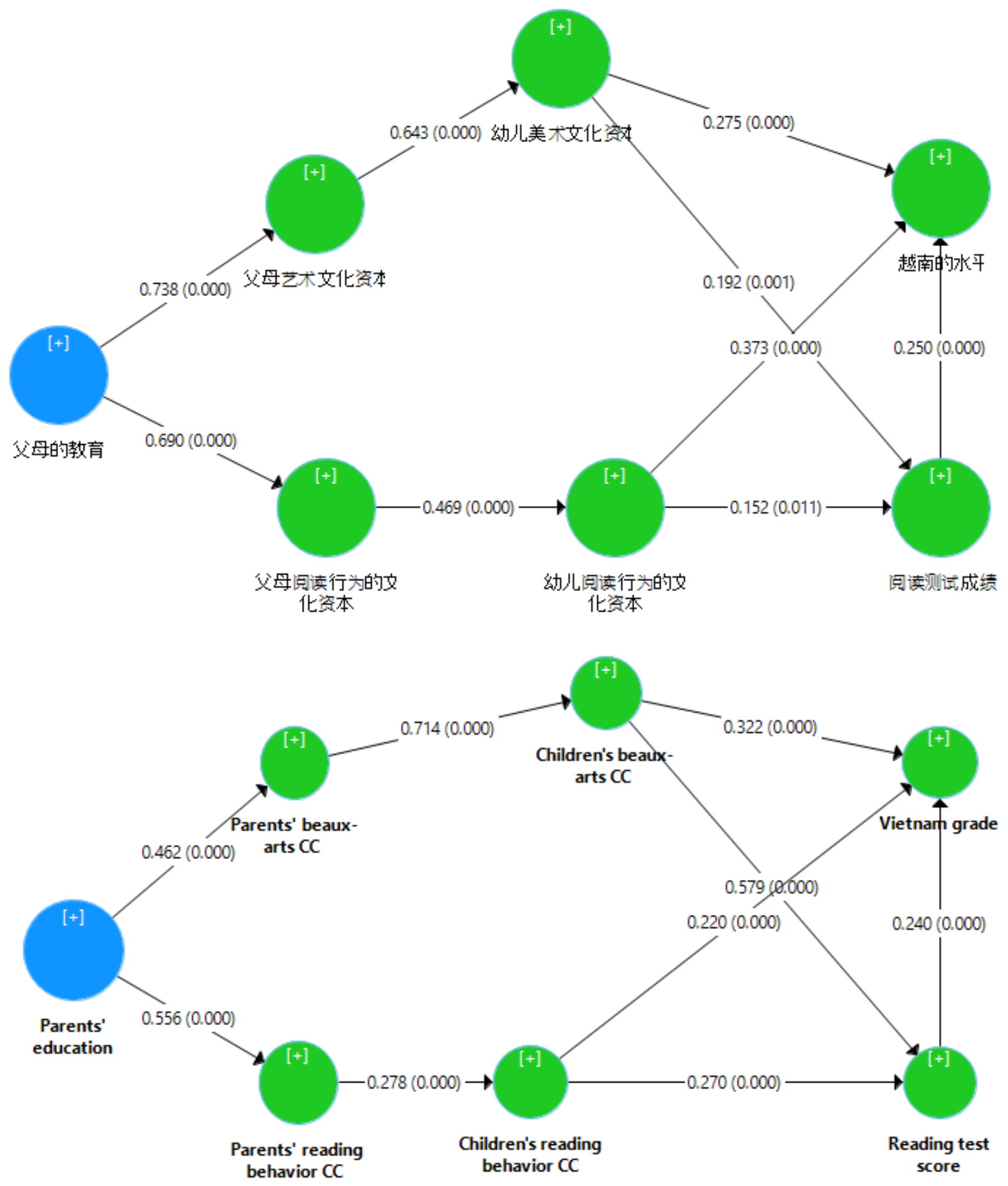

Figure 1. Structural Equation Modelling (path coefficient and p-value).

\section{Discussion}

The hypothesized model estimated well with ( $\mathrm{p}$-value $<0.05$ ), and SRMR $=0.04$. Figure 1 , reflects the significance of model and hypotheses employed. Moreover, parents' education transfer CC to their children's. it can be shown positive and significant link between parents and children's beaux-arts consumption (beta $=0.714, \mathrm{p}<0.05$ ), and relationship between parents' and children's reading behavior CC $($ beta $=0.278, \mathrm{p}<0.0 .5)$. 
The hypothesis 1a children's reading behavior CC is positively and significantly related to reading test scores. An increase of one standard deviation in children's reading behavior is linked to of 0.04 in reading test scores. However, H1a supported with (beta $=2.70$, and p-value $<0.05$ ), this result of the hypothesis found consistent with [71]. In addition, the relationship between children's beaux-arts consumption is positively linked with reading competence test score with (beta $=0.58$, and $p$-value $=0.000$ ). Therefore, H1b supported. The rise of single standard deviation in CBC will increase $4.0 \%$ standard deviation in Vietnam grades. This outcome of the study inconsistent with [72].

The hypothesis 2a estimated that there is positive and significant relationship between CRB and Vietnam grades, hypothesis found supported with ( $b e t a=0.28, S . D=0.05$, and $p$-value $<0.05$ ). This result of the study found consistent with [73, 74], who studied the positive link among CRB and school grades. Furthermore, $\mathrm{H} 2 \mathrm{~b}$ also supported with ( $\mathrm{beta}=0.46, \mathrm{~S} . \mathrm{D}=0.05$, and $\mathrm{p}$-value $=0.000$ ). Hence, the relationship between $\mathrm{CBC}$ and Vietnam grades confirmed. This hypothesis outcome found consistent with previous work of [75].

The H3a and $b$ shown the mediation of parents' reading behavior and parents' beaux-arts CC. Indeed this study corroborated the partial mediation between parents' education and CRB (H3a), and CBC (H3b). These findings of the study consistent with [76].

\subsection{Future research and implications}

The present study results demonstrate the necessities for upcoming research on the relationship among CC and educational outcomes. This study proposed that it is significant to pay greater attention towards the distinct dimension of CC and the used measures of educational outcomes. Moreover, the contentious debate on symbolic versus skill producing mechanism in prior scholarship may be limited due to distinct measurement and operationalization of CC. For example, [77], conclude that CC has no any function of symbolic except possession of books reading. In addition, scholars were interested in investing the symbolic function of CC should also employ a subjective measure despite of a standardized test scores to elude symbolic role.

Moreover, the future work should examine the children's conversion of CC more openly via investing more detailed information on teacher-student interaction and teachers' judgmental mechanism. This may also offers more valuable information on facets of children's CC that are largely focus nowadays'. From policy viewpoint this study proposed that social incline in Vietnam grades can be eased by two determinants. First, reading habits within students from low socio-economic culture may enhance their reading capability and narrow down the achievement gap. Second, raising objectivity of teachers' grading mechanism may weaken the Vietnam grading difference among high and low student by decreasing CC bias. Moreover, this work proposed that $\mathrm{CC}$ as a whole has neither a purely functional value nor a symbolic.

\section{Conclusion}

This study aimed to focus on how children's CC is transmitted into educational success. Prior research suggested two description for the relationship between children's CC and educational success: First, children's CC may prone to improve educational results as it biases teachers' subjective performance measurement. Second, children's CC may leads to children's skill establishment and also leads to enhance educational attainment. The previous scholarships given less attention to association among CC and educational success as that two dimensions of CC may leads to distinct conversion mechanism. Whereas, the beaux-arts dimension of CC is probable to impacts teachers' subjective judgment, and the reading behavior dimension is more possible to effects educational competencies [78]. Thus, this study contribute to literature by separating conversion mechanisms (symbolic and skill producing) and by connecting these mechanisms to two separate dimensions (consumptive and active) of children's CC. 


\subsection{Limitation}

This research is also not free from limitation. Due to data limitation we employed classical operationalization of CC and assessed two dimensions with limited items. The operationalization of the study limited in capturing children's CC as it be nowadays. Another limitation includes indirect approach employed to observe the suggested conversion mechanism, albeit the consequent conclusions about their credibility by changing the dependent construct.

\section{Acknowledgment}

This study did not receive any specific grant from funding agencies in the public, commercial, or not-forprofit organizations.

\section{Ethical statement}

No ethical approval is required for this study.

\section{Conflicts of interest}

The author has declared no conflicts of interest. 
References

1. Willis, P. (1981). Cultural production is different from cultural reproduction is different from social reproduction is different from reproduction. Interchange, 12(2-3), 48-67.

2. Bourdieu, P. (1986). The forms of capital.

3. Vongprateep, K. P. (2014). Parents' social and cultural capital: One parent group's influence on student engagement in an upper middle class high school. University of Redlands,

4. Dika, S. L., \& Singh, K. (2002). Applications of social capital in educational literature: A critical synthesis. Review of educational research, 72(1), 31-60.

5. Lareau, A., \& Weininger, E. B. (2003). Cultural capital in educational research: A critical assessment. Theory and society, 32(5-6), 567-606.

6. Wang, H. (2011). The effects of cultural capital on educational aspirations among adolescents in Macau. Chinese Sociological Review, 44(2), 52-75.

7. DiMaggio, P. (1992). TWO Cultural Boundaries and Structural Change: The Extension of the High Culture Model to Theater, Opera, and the Dance, 1900-1940. Cultivating differences: Symbolic boundaries and the making of inequality, 21.

8. Stanton-Salazar, R. D. (1997). A social capital framework for understanding the socialization of racial minority children and youths. Harvard educational review, 67, 1-40.

9. Wildhagen, T. (2009). Why does cultural capital matter for high school academic performance? An empirical assessment of teacher-selection and self-selection mechanisms as explanations of the cultural capital effect. The Sociological Quarterly, 50(1), 173-200.

10. Gaddis, S. M. (2013). The influence of habitus in the relationship between cultural capital and academic achievement. Social science research, 42(1), 1-13.

11. Lareau, A., \& Horvat, E. M. (1999). Moments of social inclusion and exclusion race, class, and cultural capital in family-school relationships. Sociology of education, 37-53.

12. Vassenden, A., \& Jonvik, M. (2019). Cultural capital as a hidden asset: Culture, egalitarianism and inter-class social encounters in Stavanger, Norway. Cultural Sociology, 13(1), 37-56.

13. Bloodworth, J. (2016). The Myth of Meritocracy: Why Working-Class Kids Still Get Working-Class Jobs (Provocations Series): Biteback Publishing.

14. Huang, H., \& Lin, X. (2019). Chinese parental involvement and class-based inequality in education: the role of social networking sites. Learning, Media and Technology, 44(4), 489-501.

15. Warde, A. (2017). Reassessing Cultural Capital. In Consumption (pp. 127-153): Springer.

16. Shliselberg, R., \& Givoni, M. (2018). Motility as a policy objective. Transport reviews, 38(3), 279-297.

17. Krarup, T., \& Munk, M. D. (2016). Field theory in cultural capital studies of educational attainment. British Journal of Sociology of Education, 37(5), 761-779.

18. Flemmen, M., Jarness, V., \& Rosenlund, L. (2018). Social space and cultural class divisions: the forms of capital and contemporary lifestyle differentiation. The British Journal of Sociology, 69(1), 124-153.

19. Coskuner-Balli, G., \& Thompson, C. J. (2013). The status costs of subordinate cultural capital: At-home fathers' collective pursuit of cultural legitimacy through capitalizing consumption practices. Journal of Consumer Research, 40(1), 19-41.

20. Verter, B. (2003). Spiritual capital: Theorizing religion with Bourdieu against Bourdieu. Sociological theory, 21(2), 150-174.

21. DiMaggio, P. (1982). Cultural capital and school success: The impact of status culture participation on the grades of US high school students. American sociological review, 189-201.

22. Lamont, M., \& Lareau, A. (1988). Cultural capital: Allusions, gaps and glissandos in recent theoretical developments. Sociological theory, 153-168.

23. Yeröz, H. (2019). Manifestations of social class and agency in cultural capital development processes. International Journal of Entrepreneurial Behavior \& Research. 
24. Thuy, T. T. H., \& Qalati, S. A. (2020). Preschool Teacher's Attitude towards the Integration of Information Technology into English Teaching for Young Children in Vietnam. International Journal of Economics, Commerce and Management, VIII(2), 279-294.

25. De Graaf, N. D., De Graaf, P. M., \& Kraaykamp, G. (2000). Parental cultural capital and educational attainment in the Netherlands: A refinement of the cultural capital perspective. Sociology of education, 92-111.

26. Anheier, H. K., Gerhards, J., \& Romo, F. P. (1995). Forms of capital and social structure in cultural fields: Examining Bourdieu's social topography. American journal of sociology, 100(4), 859-903.

27. De Graaf, P. M. (1986). The impact of financial and cultural resources on educational attainment in the Netherlands. Sociology of education, 237-246.

28. Aschaffenburg, K., \& Maas, I. (1997). Cultural and educational careers: The dynamics of social reproduction. American sociological review, 573-587.

29. Spillman, L. (2020). What is Cultural Sociology? : John Wiley \& Sons.

30. Stuber, J. M. (2011). Inside the college gates: How class and culture matter in higher education: Lexington Books.

31. Yosso*, T. J. (2005). Whose culture has capital? A critical race theory discussion of community cultural wealth. Race ethnicity and education, 8(1), 69-91.

32. Miller, K., Hilgendorf, A., \& Dilworth-Bart, J. (2014). Cultural capital and home-school connections in early childhood. Contemporary Issues in Early Childhood, 15(4), 329-345.

33. Xie, C., \& Ma, Y. (2019). The mediating role of cultural capital in the relationship between socioeconomic status and student achievement in 14 economies. British Educational Research Journal, 45(4), 838-855.

34. Mendoza Cazarez, D. C. (2017). Analysing educational transitions in upper secondary and higher education in Mexico. An empirical application of the capability approach and sociological perspectives on inequalities in education.

35. Sokolov, M. (2019). Cultural capital and social revolution: Arts consumption in a major Russian city, 1991-2017. Poetics, 72, 1-16.

36. Jæger, M. M., \& Breen, R. (2016). A dynamic model of cultural reproduction. American journal of sociology, 121(4), 1079-1115.

37. Kingston, P. W. (2001). The unfulfilled promise of cultural capital theory. Sociology of education, 88-99.

38. Kiuru, N., Aunola, K., Torppa, M., Lerkkanen, M.-K., Poikkeus, A.-M., Niemi, P., et al. (2012). The role of parenting styles and teacher interactional styles in children's reading and spelling development. Journal of school psychology, 50(6), 799-823.

39. Claussen, S., \& Osborne, J. (2013). Bourdieu's notion of cultural capital and its implications for the science curriculum. Science Education, 97(1), 58-79.

40. Tzanakis, M. (2011). Bourdieu's social reproduction thesis and the role of cultural capital in educational attainment: A critical review of key empirical studies. Educate , 11(1), 76-90.

41. Breinholt, A., \& Jæger, M. M. (2020). How does cultural capital affect educational performance: Signals or skills? The British Journal of Sociology, 71(1), 28-46.

42. Negewo, M. A., \& Murugan, P. (2018). Cultural Capital and Students' Academic Performance: The Case of Ethiopian Higher Educational Institutions. Eastern Africa Social Science Research Review, 34(1), 249-276.

43. Muenks, K., Wigfield, A., \& Eccles, J. S. (2018). I can do this! The development and calibration of children's expectations for success and competence beliefs. Developmental Review, 48, 24-39.

44. Lavy, V., \& Megalokonomou, R. (2019). Persistency in Teachers' Grading Bias and Effects on LongerTerm Outcomes: University Admissions Exams and Choice of Field of Study. National Bureau of Economic Research.

45. epdc (2019). Vietnam.

46. GSOV (2020). Education. 
47. Saito, E., Atencio, M., Khong, T. D. H., Takasawa, N., Murase, M., Tsukui, A., et al. (2018). The teacher as a 'colony': a case study of agentive responses to 'colonising'education policy in Vietnam. Cambridge Journal of Education, 48(1), 65-86.

48. Nguyen, H. T. (2012). What role do race, ethnicity, language and gender play in the teaching profession? Race ethnicity and education, 15(5), 653-681.

49. Burton, J., Horowitz, R., \& Abeles, H. (1999). Learning in and through the arts: Curriculum implications. Champions of change: The impact of the arts on learning, 35-46.

50. Goldstein, H. (1979). Consequences of using the Rasch model for educational assessment. British Educational Research Journal, 5(2), 211-220.

51. Gehrer, K., Zimmermann, S., Artelt, C., \& Weinert, S. The Assessment of Reading Competence (Including Sample Items For Grade 5 and 9) Status: 2012.

52. Campbell, F. A., \& Ramey, C. T. (1994). Effects of early intervention on intellectual and academic achievement: a follow-up study of children from low-income families. Child development, 65(2), 684698.

53. Hampden-Thompson, G., \& Galindo, C. (2017). School-family relationships, school satisfaction and the academic achievement of young people. Educational Review, 69(2), 248-265.

54. Hair, J., Hollingsworth, C. L., Randolph, A. B., \& Chong, A. Y. L. (2017). An updated and expanded assessment of PLS-SEM in information systems research. Industrial Management $\mathcal{E}$ Data Systems.

55. Ali, F., Rasoolimanesh, S. M., Sarstedt, M., Ringle, C. M., \& Ryu, K. (2018). An assessment of the use of partial least squares structural equation modeling (PLS-SEM) in hospitality research. International Journal of Contemporary Hospitality Management.

56. Nicolescu, L., \& Nicolescu, C. (2019). Using PLS-SEM to build an employability confidence model for higher education recipients in the field of business studies. Kybernetes.

57. Qalati, S. A., \& Kwabena, G. (2019). Influence of Brand Equity on Brand Performance: Role of Brand Reputation and Social Media. International Journal of Research and Review, 6(9), 304-317.

58. Hair, J. F., Black, W. C., Babin, B. J., \& Anderson, R. E. (2010). Multivariate data analysis: Global edition. Pearson Higher Education Upper Saddle River, NJ.

59. Henseler, J., Ringle, C. M., \& Sinkovics, R. R. (2009). The use of partial least squares path modeling in international marketing. In New challenges to international marketing (pp. 277-319): Emerald Group Publishing Limited.

60. Nunnally, J. (1978). Psychometric methods. New York: McGraw-Hill.

61. Bagozzi, R. P., \& Yi, Y. (1988). On the evaluation of structural equation models. Journal of the academy of marketing science, 16(1), 74-94.

62. Fornell, C., \& Larcker, D. F. (1981). Evaluating structural equation models with unobservable variables and measurement error. Journal of marketing research, 18(1), 39-50.

63. Gold, A. H., Malhotra, A., \& Segars, A. H. (2001). Knowledge management: An organizational capabilities perspective. Journal of management information systems, 18(1), 185-214.

64. Hair, J. F., Ringle, C. M., \& Sarstedt, M. (2011). PLS-SEM: Indeed a silver bullet. Journal of Marketing theory and Practice, 19(2), 139-152.

65. Cohen, J. (1998). Statistical Power Analysis for the Behavioural Sciences, xxi. Hillsdale, NJ: L Erlbaum associates.

66. Falk, R. F., \& Miller, N. B. (1992). A primer for soft modeling: University of Akron Press.

67. Cohen, J. (2013). Statistical power analysis for the behavioral sciences: Routledge.

68. Ringle, C. M., Sarstedt, M., \& Straub, D. (2012). A critical look at the use of PLS-SEM in MIS Quarterly. MIS Quarterly (MISQ), 36(1).

69. Geisser, S. (1974). A predictive approach to the random effect model. Biometrika, 61(1), 101-107.

70. Stone, M. (1974). Cross-validatory choice and assessment of statistical predictions. Journal of the Royal Statistical Society: Series B (Methodological), 36(2), 111-133. 
71. Muntoni, F., \& Retelsdorf, J. (2019). At their children's expense: How parents' gender stereotypes affect their children's reading outcomes. Learning and Instruction, 60, 95-103.

72. Albright, J., Gore, J., Smith, M., \& Holmes, K. (2018). Operationalizing Bourdieu for the study of student aspirations: Conceptual and methodological challenges. International Perspectives on Theorizing Aspirations: Applying Bourdieu's Tools, 83.

73. Boonk, L., Gijselaers, H. J., Ritzen, H., \& Brand-Gruwel, S. (2018). A review of the relationship between parental involvement indicators and academic achievement. Educational Research Review, 24, 10-30.

74. Morgan, P. L., \& Fuchs, D. (2007). Is there a bidirectional relationship between children's reading skills and reading motivation? Exceptional children, 73(2), 165-183.

75. De Graaf, N. D., \& De Graaf, P. M. (2002). Formal and popular dimensions of cultural capital: Effects on children's educational attainment.

76. Mikus, K., Tieben, N., \& Schober, P. S. (2019). Children's conversion of cultural capital into educational success: the symbolic and skill-generating functions of cultural capital. British Journal of Sociology of Education, 1-19.

77. Medeiros, M. A., \& Henriksen, T. (2019). Race and Employment Practices in Northeast Brazil's Ecotourism Industry: An Analysis of Cultural Capital, Symbolic Capital, and Symbolic Power. Latin American Research Review, 54(2).

78. Hough, M. K. (2019). The impact of professional development through a graduate course on multimedia technology on teachers' beliefs about multimedia and their implementation of multimedia into their teaching practice, including to meet the Common Core state standards. Rutgers University-Graduate School of Education, 